\title{
Quantification of Alcohol Dehydrogenase Concentration for Traumatic Brain Injury in Alcohol-intoxicated Patients as a Predictor of Severity and Prognosis
}

\author{
Muhammad Z. Arifin ${ }^{1}$, David Atmaja ${ }^{2}$, Ahmad Faried ${ }^{1 *}$ \\ ${ }^{1}$ Department of Neurosurgery, Faculty of Medicine, Universitas Padjadjaran, Dr. Hasan Sadikin Hospital, Bandung, West Java, \\ Indonesia; ${ }^{2}$ Department of Neurosurgery, Eka Hospital, Pekanbaru, Riau, Indonesia
}

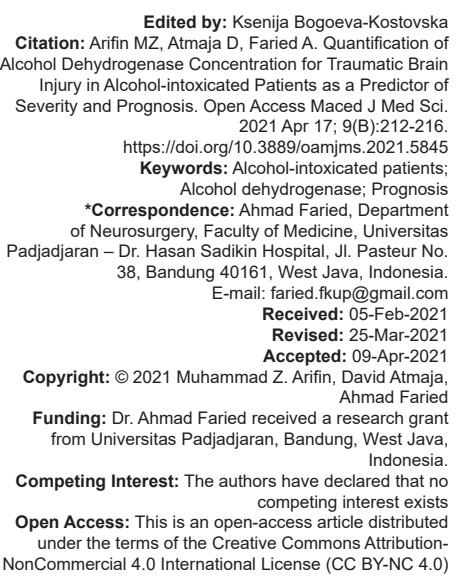

\section{Abstract}

BACKGROUND: Traumatic brain injury (TBI) stills the leading cause of public health problem and disabilities in many countries, especially in lower-middle-income countries. Motor vehicle crashes, especially motorized twowheeler riders, are the major cause of TBI, followed by fall and assault. During 2013-2014, a total of 2108 TB cases $(65.4 \%$ of them being caused by motor vehicle crashes) were documented in the Emergency Unit of Dr. Hasan Sadikin Hospital (RSHS) Bandung. Among these, $30.7 \%$ of cases were categorized as moderate and severe TBI, with a mortality rate of $29.2 \%$. Half of the cases arrived at RSHS within $6 \mathrm{~h}$ and $14.0 \%$ of these cases were alcohol-intoxicated. Individuals with low activity of alcohol-metabolizing enzymes have low tolerance to alcohol and are therefore rapidly intoxicated, making them more susceptible to more serious injuries from motor vehicle crashes.

METHODS: A prospective study was designed by consecutive sampling from January to August 2017 to review 30 intoxicated patients with TBI on hospital admission by measuring their serum alcohol dehydrogenase (ADH) concentration using an ELISA and then correlated it with the severity, type of TBI lesions, and the outcome.

RESULTS: Demonstrated an ADH level of I d0.24 ng/ml in patients with TBI with a history of alcohol intoxication which statistically correlated with lower initial Glasgow coma scale (GCS) scores on admission by approximately 6.53 times $(p<0.001)$, thus increasing the risk of developing multiple lesions by 3.98 times $(p=0.029)$ and worse outcomes by 5.27 times $(p=0.003)$, but it did not correlate with length of stay $(p=0.392)$

CONCLUSIONS: ADH concentrations in intoxicated TBI patients can be taken into consideration to decide about the therapeutic action and further informed consent to the family.

\section{Introduction}

Traumatic brain injury (TBI) remains a huge community health and socio-economic problem throughout the world [1]. In the United States (US), the leading cause of death is trauma among people aged gedee Un, and the risk of TBI is higher corresponding to inappropriate use of alcohol [2]. The evidence that corresponds with alcohol and road trauma remains reserved in most of the Western Pacific nations. Approximately $4 \%$ of global deaths are due to alcohol use and are primarily associated with trauma [3]. Almost half of these alcohol-related deaths due to trauma occur in the prehospital environment. Obviously, about $35 \%$ $81 \%$ of wounded patients were found to be alcoholintoxicated and about $42 \%$ of patients with TBI were chronic alcoholics before injury [4].

Alcohol as a risk factor for highway trauma is particularly important, especially in low-resource nations [3]. Consecutive injuries and highway accidents are the leading risk factors arising from alcohol consumption [3]. According to the World Health
Organization, public highway accidents would become the third significant cause of universal burden of both disease and injury by the year 2020 [1]. Approximately 1.24 million people die every year as an outcome of road traffic accidents, the eighth primary cause of worldwide deaths [3]. According to the Global Road Safety Status Report, in 2013, 28 countries representing 449 million people $(7 \%$ of the world oximately $4 \%$ of $x y$ adequate laws that addressed five major risk factors (speed, drunk driving, helmets, seat belts, and child safety) for traffic crashes [5]. This implies that several nations have applied road safety measures, and more measures have to be implemented to reduce traffic injuries and fatal deaths caused by alcohol [3]. Alcohol intoxication is widely known as a risk factor for TBI, and almost half of the patients with TBI were under the influence of alcohol at the moment of injury or trauma [6]. A study from Indonesia reported that the incidence and mortality of TBI at Dr. Hasan Sadikin Hospital (RSHS), Bandung, are still high [7]. Although an increased number of traffic crashes was documented in the region, there is still a lack of data on the epidemiology of TBI in Indonesia. A total of 2108 head injuries were registered in our 
emergency unit during 2014, of which $65.4 \%$ were caused by motorcycle crashes. Of these cases, $30.7 \%$ were categorized as moderate or severe TBI, with a mortality rate of $29.2 \%$. More than half of the cases arrived at the emergency unit within $6 \mathrm{~h}$, and $14.0 \%$ of them were under alcohol intoxication [8].

Alcohol dehydrogenase $(\mathrm{ADH})$ and aldehyde dehydrogenase (ALDH) are the principal enzymes involved in the catabolism of ethanol. Alcohol is initially metabolized by ADH to acetaldehyde, which is consequently oxidized by ALDH to acetic acid. Individuals with low activity of alcohol-metabolizing enzymes have low tolerance to alcohol and are therefore rapidly intoxicated [9]. Our study aim was to correlate the concentration of $\mathrm{ADH}$ in $\mathrm{TBI}$ patients with the severity, type of TBI lesion, Glasgow coma scale (GCS) score in the final outcome, and length of stay.

\section{Methods}

This was a single-institution retrospective study conducted at RSHS in Bandung, which serves the city, and patients are also referred from West Java Province. RSHS in Bandung is one of the 15 hospitals that have an emergency department and an accompanying intensive care unit in West Java Province. The hospital has 900 beds, and the neurosurgery unit at RSHS admits an average of 117 trauma patients every month. Data were collected from patients who presented to RSHS from January 1 to August 31, 2017. The inclusion criteria were a confirmed diagnosis based on ICD-10 of TBI with a history of alcohol abuse with intoxication (Concussion S06.0 with F10.129) and agreeing to undergo a blood test. Patients who refused to participate in the study were excluded from the study. A database was constructed by reviewing the medical records, which included de-identified data for each eligible patient unit at RSHSic information, initial GCS score, helmet used, type of lesions, and prognosis based on GCS score when the patient was discharged home (improvement, no improvement, or death), including the length of stay. De-identified data were entered into Microsoft Excel 2010 and analyzed using Stata 14 . Bivariate logistic regression was performed to evaluate the relationship between each of these variables and $\mathrm{ADH}$ concentration. Multivariate logistic regression models were constructed to estimate the association of all variables and ADH concentration.

\section{Results}

From January to August 2017, a total of 30 head injury cases with alcohol intoxication were registered at the hospital; all used motorized two-wheelers and were males $(100 \% ; n=30)$. The majority of them were aged ere agerity $90 \% ; n=30$ ) and had mild head injury (GCS score, 14-15; 50\%), followed by moderate (GCS score, 9-13; 43\%) and severe head injury (GCS score, 3-8; $7 \%$ ). Patients had craniomaxillofacial lesion $(63.3 \%$; $\mathrm{n}=19)$, intracranial lesion $(23.3 \% ; n=7)$, spinal cord lesion $(3.4 \% ; n=1)$, and multiple lesions $(10 \% ; n=3)$. Improvement in final outcome was observed in $86.7 \%$ of patients (GCS score, 14derate (GCS score, 9-13; 43\%) and severe headand $13.3 \%$ of patients died $(n=4)$. Among patients with TBI associated with motorcycle crashes, less than half were wearing a helmet at the time of the crash $(46.7 \% ; n=14)$. Patients with length of stay patients died $(n=4) . A \%(n=11)$ and mandth of stay patients $\%(n=4)$, and $30 \%(n=15)$ had forced discharge (Table 1).

Table 1: Characteristics of patients with or without intoxicated TBI

\begin{tabular}{|c|c|c|}
\hline Characteristic Intoxicated $(n=30)$ & \multicolumn{2}{|c|}{ Not intoxicated $(n=10)$} \\
\hline \multicolumn{3}{|l|}{ Age } \\
\hline$<17$ years old & 3 & 10 \\
\hline$\geq 17$ years old & 27 & 0 \\
\hline \multicolumn{3}{|l|}{ Gender } \\
\hline Man & 30 & 9 \\
\hline Women & 0 & 1 \\
\hline \multicolumn{3}{|l|}{ Initial GCS } \\
\hline Mild (14-15) & 15 & 8 \\
\hline Moderate (9-13) & 13 & 2 \\
\hline Severe $(<8)$ & 2 & 0 \\
\hline \multicolumn{3}{|l|}{ Type of lesion } \\
\hline Cranio-maxillo-facial $^{a}$ & 19 & 7 \\
\hline Intracranial $^{b}$ & 7 & 0 \\
\hline Spinal cord injury & 1 & 0 \\
\hline Multipel $^{c}$ & 3 & 3 \\
\hline \multicolumn{3}{|l|}{ Outcome } \\
\hline Improvement (GCS 14-15) & 26 & 10 \\
\hline Death & 4 & 0 \\
\hline No improvement & 0 & 0 \\
\hline \multicolumn{3}{|l|}{ Protection } \\
\hline Using helmet & 14 & 7 \\
\hline No helmet & 16 & 3 \\
\hline \multicolumn{3}{|l|}{ Length of stay } \\
\hline$<1$ week & 11 & 9 \\
\hline$>1$ weeks & 4 & 1 \\
\hline Forced discharge & 15 & 0 \\
\hline
\end{tabular}

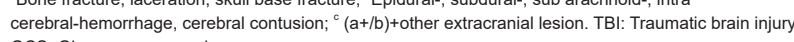
GCS: Glasgow coma scale.

Of all the ten head injury cases without alcohol intoxication, included as the control group, the majority of them also used motorized two-wheelers and were males $(90 \% ; n=9)$. All were aged $<17$ years $(100 \%)$ and had mild head injury (GCS score $143.3 \%$; $\mathrm{n}=7$ ), spinal cordderate (GCS score 9cases without ao severe head injury (GCS score 3the control group, the majority of them also used motorized two-wheelers and were males $(90 \% ; n=9)$. All were aged $<17$ years $(100 \%)$ and had mild head injury (GCS score $143.3 \%$. All patients $(100 \%)$ showed improvement in the final outcome (GCS score 14-15; $n=10$ ). Among patients with TBI associated with motorcycle crashes, $70 \%$ $(n=7)$ of them were wearing a helmet at the time of the crash. Patients with length of stay s with TBI associate\% $(n=9)$, whereas those with length of stay $s$ with TBI associate \% $(n=10)$ (Table 1).

Regarding $\mathrm{ADH}$ concentration in the trauma patients, all the 30 patients with alcohol intoxication had an average of $17.17 \mathrm{ing} \mathrm{ADHng} / \mathrm{ml}$ (range 4.93 
Table 2: ADH Concentration Patients with or without Intoxicated TBI

\begin{tabular}{lll}
\hline Variable & ADH intoxicated $(\mathrm{ng} / \mathrm{ml})(\mathrm{n}=30)$ & ADH not intoxicated $(\mathrm{ng} / \mathrm{ml})(\mathrm{n}=10)$ \\
\hline Mean $\pm \mathrm{SD}$ & $17.17 \pm 8.45$ & $41.57 \pm 7.66$ \\
Minimum value & 4.93 & 32.24 \\
Maximum value & 33.5 & 52.92 \\
\hline TBl: Traumatic brain injury, ADH: Alcohol dehydrogenase.
\end{tabular}

nge. $5 \mathrm{ng} / \mathrm{ml}$ ). In the control group, the average ADH concentration of all the ten patients was 41.57 ts was $\mathrm{ng} / \mathrm{ml}$ (range 32.2457 centrng $/ \mathrm{ml}$ ) (Table 2). The average ADH concentrations were 22.28 trationng $/ \mathrm{ml}$ in patients with mild GCS score, 13.19 ts with $\mathrm{ng} / \mathrm{ml}$ in those with moderate GCS score, and $5.633 \mathrm{~s}$, alng $/ \mathrm{ml}$ in patients with severe GCS score (Table 3).

Table 3: ADH Concentration of Intoxicated TBI Patients based on Initial GCS

\begin{tabular}{llll}
\hline Variable & Mild $(\mathrm{ng} / \mathrm{ml})(\mathrm{n}=15)$ & Moderate $(\mathrm{ng} / \mathrm{ml})(\mathrm{n}=13)$ & Severe $(\mathrm{ng} / \mathrm{ml})(\mathrm{n}=2)$ \\
\hline Mean \pm SD & $22.28 \pm 8.41$ & $13.19 \pm 3.93$ & $5.63 \pm 0.41$ \\
Minimum value & 4.93 & 8.85 & 5.92 \\
Maximum value & 33.5 & 20.9 & 5.34 \\
\hline TBI: Traumatic brain injury, ADH: Alcohol dehydrogenase, GCS: Glasgow coma scale.
\end{tabular}

The results of the nonparametric Spearman correlation test revealed significantly negative correlations between ADH concentration and initial GCS score $r=$ initial GCS score (aramconcentration and the type of lesion $r=$ the type of lesion (rametriconcentration and outcome $r=$ outcome $f$ lesion rametric Spearman correlation test revealed significaconcentration and length of stay $(r=0.162 ; p=0.392)$ (Table 4).

Table 4: ADH of Intoxicated TBI versus initial GCS, type of lesion, outcome, and length of stay

\begin{tabular}{lcl}
\hline Variables & Non parametric test value & $p$-value \\
\hline ADH versus initial GCS & -0.653 & $0.000^{*}(p<0.05)$ \\
ADH versus type of lesion & -0.398 & $0.029^{*}(p<0.05)$ \\
ADH versus outcome & -0.527 & $0.003^{*}(p<0.05)$ \\
ADH versus length of stay & 0.162 & $0.392(p<0.05)$ \\
\hline TBI: Traumatic brain injury, ADH: Alcohol dehydrogenase, GCS: Glasgow coma scale.
\end{tabular}

\section{Discussion}

The risk of a crash with alcohol consumption varies with age and drinking experience. Zador estimated that crash rates of male drivers aged 16ed 16 that crash rates 3 times the estimated crash rate of male drivers aged ith age a [10]. Our result is similar to that of the aforementioned study, wherein all our patients were male drivers aged $16 e d 16$ that crash study on drivers killed in road crashes estimated that teenage drivers had more than 5 times the risk of a crash compared with drivers aged oned study, wherein all our patients were male drivers aged 16 ed 16 that crash study on drivers killed in roadcentrations (ad cras 3 times higher risk than drivers aged rivers ag [11]. A study in the US indicated that motorized two-wheeler riders have higher intoxication rates than motor vehicle drivers [12]. A relative study on fatality risks at different BAC levels indicated that for single-vehicle crashes, each $0.02 \%$ increase in BAC levels approximately doubled the risk of involvement in a fatal crash [10].
Drinking and driving have been pointed out as one of the determining factors for the occurrence of crashes. Faced with this problem, the Republic of Indonesia the determining factors concerning Road Traffic and Transportation in Article 106 of the Law in Paragraph 1 states that everyone who drives a motor vehicle on the road must drive their vehicle in alert and full concentration. The explanation of the article and this paragraph states that the meaning of led the risk of involvement in a fatal crashad more than $\%$ ) had multiple lesions $80 \%$ ), followed by monot be distracted due to illness, fatigue, sleepiness, using a telephone or watching television or videos installed in a vehicle, or drinking liquid containing alcohol or drugs that would affect the ability to drive the vehicle. The legal blood alcohol limits and breath content limits in several countries around the world are typically $0.08 \mathrm{~g} / \mathrm{dl}$.

Alcohol test is generally performed by measuring the alcohol levels in blood, breath, or urine. Till date, various types of tools have been developed to detect alcohol levels, ranging from simple to complex ones. Vukovic et al. stated that factual BACs and related expert toxicological decision based solely on the results obtained from breath analyzers might not be correct [13]; however, in an emergency setting, it is difficult to perform a breath analyzer test because most of the patients with TBI cannot obey the command and/or have a decreased level of consciousness. Individuals with a low activity of ADH (alcohol-metabolizing enzymes) have low tolerance to alcohol and are therefore rapidly intoxicated [9]; in other words, they are more vulnerable to more serious injuries from motor vehicle crashes. In the present study, the average $\mathrm{ADH}$ concentration in the control group was $41.57 \mathrm{a} 7.66 \mathrm{ng} / \mathrm{ml}$, whereas it was $17.17 \mathrm{~h} 8.45 \mathrm{ng} / \mathrm{ml}$ in the intoxication group. This result is consistent with a previous study showing that the normal ADH concentration in plasma or serum is $59 \mathrm{um} \mathrm{ng} / \mathrm{ml}$ based on ELISA [14] and ADH has been reported to be low in alcoholics, it low activity contribute to the reduced first pass ethanol metabolism associated with raised ethanol blood concentrations in these people. [15].

Alcohol contributes significantly to mortality and morbidity in trauma patients, despite the type of the injury [4]. Most of our patients with TBI (64.5\%) were under alcohol intoxication, whereas only falls contributed to the mild head injury category. However, we speculated that there is a difference in alcohol consumption due to the different culture of Asian and Western youth, as the levels of ethanol have been found to be high in victims of road traffic crashes in Western countries, associated with high mortality rates, compared with Asian youth who could not afford legal alcohol consumption and often turn to bootleg alcohol or local moonshine or primarily alcohol containing methanol that is locally known as that is locally rily alcohol 
Our results demonstrated significantly negative correlation between ADH concentration and initial GCS score; thus, we conclude that patients with TBI with a history of alcohol intoxication and an ADH concentration of $\leq f$ centng $/ \mathrm{ml}$ have a relative influence of lower initial GCS scores by as much as 6.53 times $(p=0.000)$. However, in fact, this prediction might vary for each case, as there are several influencing factors such as the type of the alcohol (true ethanol or rmiras oplosannplosanct, this , this prediction might $v$ the period between alcohol consumption and admission to the hospital. There was also a significantly negative correlation between $\mathrm{ADH}$ concentration and the type of lesion; the lower the ADH concentration, the more likely the patient has a 3.98 times probability of multiple lesions ( $p$ $=0.029$ ). In addition, the correlation between ADH concentration and the outcome was significantly negative, namely, improvement, no improvement, or death. The lower the ADH concentration, the more likely the patient has a 5.27 times probability of worse outcomes $(p=0.003)$. In this study, we did not find a significant correlation between ADH concentration and length of stay, that is, $A D H$ concentration did not affect the patientn length of stay $(p=0.392)$.

However, this study has several limitations, namely, we dony rates, data that intoxicated TBI patients who come to RSHS (whether they were chronic alcoholics, regular drinker or just a beginner), making it difficult for us to conclude the lower level of $\mathrm{ADH}$. There were also "protection against alcoholism" phenomenon in Asia people (Mongoloid); the final outcome assessment of this study did not completely describe the characteristics because most of the patients decided for forced discharged due to financial problems. Follow-up is required after the patient was forced discharged. A study is already ongoing to increase the number of samples and variations in the type of lesions, the existence of racial differences in alcohol sensitivity and also to compare with more practical BAC detection devices, such as a rapid alcohol test.

\section{Conclusions}

$\mathrm{ADH}$ concentrations $\leq \mathrm{DH}$ concentrain patients with $\mathrm{TBI}$ with a history of alcohol intoxication statistically correlated with lower initial GCS scores on admission by about 6.53 times $(p=0.000)$, which increased the risk of multiple lesions by 3.98 times $(p$ $=0.029)$ and worse final outcomes by 5.27 times $(p=$ 0.003). ADH concentrations in intoxicated TBI patients can be taken into consideration to decide about the therapeutic action and further informed consent to the family or as a legal information to the law-enforcement authority.

\section{Ethical Statement}

This study was approved by Faculty of Medicine, Universitas Padjadjaran ethics committee and has been performed in according ethical standards laid down Helsinki Declaration 1964.

\section{Authors Contributions}

All authors had examined, treated, observed, and follow-up the patients. All authors participated in writing the manuscript, had read, and approved the final manuscript.

\section{References}

1. Maas AIR, Stocchetti N, Bullock R. Moderate and severe traumatic brain injury in adults. Lancet Neurol. 2008;7(8):72841. https://doi.org/10.1016/s1474-4422(08)70164-9

PMid:18635021

2. Harris AH, LembkeA, Henderson P, Gupta S, Moos R, Bradley KA. Risk of future trauma based on alcohol screening scores: A twoyear prospective cohort study among US veterans. Addict Sci Clin Pract. 2012;7(1):6. https://doi.org/10.1186/1940-0640-7-6 PMid:22966411

3. O'Connor LR, Ruiz RAL. Alcohol and hospitalized road traffic injuries in the Philippines. Yale J Biol Med. 2014;87(3):307-19. PMid:25191146

4. Opreanu R, Kuhn D, Basson M. NIH public access the influence of alcohol on mortality in TBI. J Am Coll Surg. 2012;29(6):997-1007.

PMid:20510810

5. World Health Organization. Global Status Report On Road Safety 2013: Supporting a Decade of Action. Geneva: World Health Organization; 2013.

6. Raj R, Skrifvars MB, Kivisaari R, Hernesniemi J, Lappalainen J, Siironen J. Acute alcohol intoxication and long-term outcome in patients with traumatic brain injury. J Neurotrauma. 2015;32(2):95-100. https://doi.org/10.1089/neu.2014.3488 PMid:25010885

7. Zamzami NM, Fuadi I, Nawawi M. Incidence Rate and Outcome of Brain Injury at Dr. Hasan Sadikin Hospital, Bandung, 20082010. Jurnal Neuroanestesia Indonesia 2013;2:6.

8. Faried A, Bachani AM, Sendjaja AN, Hung YW, Arifin MZ. Characteristics of moderate and severe traumatic brain injury of motorcycle crashes in Bandung, Indonesia. World Neurosurg. 2017;100:195-200. https://doi.org/10.1016/j.wneu.2016.12.133

9. EnkhjargalTs, Gantuya P, Hishigbuyan D, Sodnomtseren B. Blood levels of alcohol dehydrogenase and aldehydedehydrogenase. Mong Med Sci J. 2013;164(2):7-10.

10. Zador PL. Alcohol-related relative risk of fatal driver injuries in relation to driver age and sex. J Stud Alcohol. 1991;52(4):30210. https://doi.org/10.15288/jsa.1991.52.302

PMid:1875701 
11. Keall MD, Frith WJ, Patterson TL. The influence of alcohol, age and number of passengers on the night-time risk of driver fatal injury in New Zealand. Accident Anal. Prev. 2004;36(1):49-61. https://doi.org/10.1016/s0001-4575(02)00114-8

PMid:14572827

12. National Highway Traffic Safety Administration. Traffic Safety Facts, 2000: Motorcycles. Washington, DC: National Highway Traffic Safety Administration; 2001. https://doi.org/10.1037/ e478152008-001

13. Vukovic J, Modun D, Markovic D, Sutlovic D. Comparison of breath and blood alcohol concentrations in a controlled drinking study. J Subst Abuse Alcohol. 2015;3(2):1029.

14. Bühler R, Von Wartburg JP. Quantitation of alcohol dehydrogenase in human tissue and serum by an enzymelinked immunosorbent assay (ELISA). Alcohol Clin Exp Res. 1982;6(4):506-11. https://doi.org/10.1111/j.1530-0277.1982. tb05014.x

PMid:6758622

15. Cederbaum Al. Alcohol metabolism. Clin Liver Dis. 2012;16(4):667-85.

PMid:23101976 